\title{
Interactive effects of multiple stressors vary with consumer interactions, stressor dynamics and magnitude
}

\author{
Mischa Turschwell ${ }^{1}$, Roman Ashauer ${ }^{2}$, Max Campbell $^{1}$, Rod Connolly ${ }^{1}$, Sean Connolly ${ }^{3}$, \\ Isabelle Cote ${ }^{4}$, Frederik De Laender ${ }^{5}$, Michelle Jackson ${ }^{6}$, Mira Kattwinkel ${ }^{7}$, Chrystal \\ Mantyka-Pringle ${ }^{8}$, Ralf Schaefer ${ }^{9}$, Michael Sievers ${ }^{10}$, Paul Van den Brink ${ }^{11}$, and Chris \\ Brown $^{1}$ \\ ${ }^{1}$ Griffith University \\ ${ }^{2}$ University of York \\ ${ }^{3}$ Smithsonian Tropical Research Institute \\ ${ }^{4}$ Simon Fraser University \\ ${ }^{5}$ Namur University \\ ${ }^{6}$ Oxford University \\ ${ }^{7}$ University Koblenz - Landau \\ ${ }^{8}$ Wildlife Conservation Society Canada \\ ${ }^{9}$ University of Koblenz Landau - Campus Landau \\ ${ }^{10}$ Griffith University - GC Campus \\ ${ }^{11}$ Wageningen University
}

December 9, 2021

\begin{abstract}
Predicting the impacts of multiple stressors is important for informing ecosystem management, but is impeded by a lack of a general framework for predicting whether stressors interact synergistically, additively, or antagonistically. Here we use processbased models to study how interactions generalise across three levels of bio-logical organisation (physiological, population, and community) for a simulated two-stressor experiment on a seagrass model system. We found that the same underlying processes could result in synergistic, additive or antagonistic interactions, with interaction type depending on initial conditions, experiment duration, stressor dynamics, and consumer presence. Our results help explain why meta-analyses of multiple stressor experimental results have struggled to identify predictors of consistently non-additive interactions in the natural environment. Experiments run over longer temporal scales, with treatments across gradients of stressor magnitude, are needed to identify the processes that underpin how stressors interact and provide useful predictions to management.
\end{abstract}

\section{Hosted file}

2021-12-01_Turschwell-etal_Seagrass-non-linear-models.docx available at https://authorea. com/users/450365/articles/548681-interactive-effects-of-multiple-stressors-vary-withconsumer-interactions-stressor-dynamics-and-magnitude 